\title{
Curtin-Hammett Paradigm for Stereocontrol in Organocatalysis by Diarylprolinol Ether Catalysts
}

DOI:

10.1021/ja300415t

Link to publication record in Manchester Research Explorer

\section{Citation for published version (APA):}

Burés, J., Armstrong, A., \& Blackmond, D. G. (2012). Curtin-Hammett Paradigm for Stereocontrol in Organocatalysis by Diarylprolinol Ether Catalysts. Journal of the American Chemical Society, 134, 6741-6750. https://doi.org/10.1021/ja300415t

\section{Published in:}

Journal of the American Chemical Society

\section{Citing this paper}

Please note that where the full-text provided on Manchester Research Explorer is the Author Accepted Manuscript or Proof version this may differ from the final Published version. If citing, it is advised that you check and use the publisher's definitive version.

\section{General rights}

Copyright and moral rights for the publications made accessible in the Research Explorer are retained by the authors and/or other copyright owners and it is a condition of accessing publications that users recognise and abide by the legal requirements associated with these rights.

\section{Takedown policy}

If you believe that this document breaches copyright please refer to the University of Manchester's Takedown Procedures [http://man.ac.uk/04Y6Bo] or contact uml.scholarlycommunications@manchester.ac.uk providing relevant details, so we can investigate your claim.

\section{OPEN ACCESS}




\title{
Curtin-Hammett Paradigm for Stereocontrol in Organocatalysis by Diarylprolinol Ether Catalysts
}

\author{
Jordi Burés, $^{\dagger}$ Alan Armstrong, ${ }^{\ddagger}$ and Donna G. Blackmond ${ }^{*}, \dagger$ \\ ${ }^{\dagger}$ Department of Chemistry, The Scripps Research Institute, La Jolla, California 92037, United States \\ ${ }^{\ddagger}$ Department of Chemistry, Imperial College London, London SW7 2AZ, U.K.
}

\section{Supporting Information}

ABSTRACT: Detailed mechanistic study of two reactions catalyzed by diarylprolinol ether catalysts, the conjugate addition of aldehydes to nitro-olefins and the $\alpha$-chlorination of aldehydes, leads to the proposal that the stereochemical outcome in these cases is not determined by the transition state of the step in which the stereogenic center is formed from enamine attack on the electrophile but instead is correlated with the relative stability and reactivity of diastereomeric intermediates downstream in the catalytic cycle. This combination of kinetic and thermodynamic factors illustrates a remarkable Curtin-Hammett scenario that

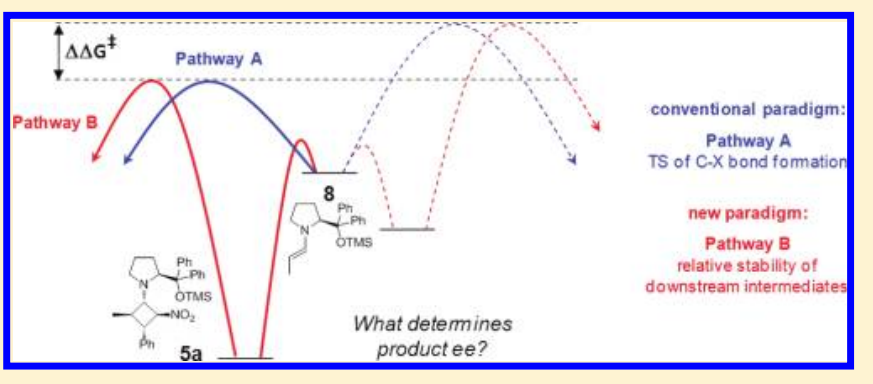
can result in either an enhancement or an erosion of the selectivity that would be predicted by the transition state for enamine attack on the electrophile. Evidence is offered to suggest that this concept may represent a general phenomenon for pyrrolidine-based catalysts lacking an acidic directing proton. Implications for catalyst and reaction design are discussed.

\section{INTRODUCTION}

Since the contemporaneous reports in 2000 of the intermolecular aldol reaction catalyzed by proline ${ }^{1}$ and the imidazolidinone-catalyzed Diels-Alder reaction, ${ }^{2}$ research in the area of asymmetric aminocatalysis has burgeoned, with a variety of efficient and selective catalysts being introduced for large number of transformations. Mechanistic models aiming to rationalize stereoselectivity for reactions thought to follow an enamine mechanism have invoked a role for Bronsted acid co-catalysis in the case of proline and related catalysts, supported by theoretical calculations in what is now known as the HoukList model (I, Scheme 1). ${ }^{3}$ A complementary model for catalysts

Scheme 1. Transition-State Models for the Stereogenic Center-Forming Step in Enamine Catalysis

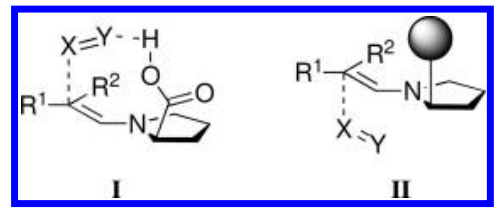

lacking a directing proton proposes that selectivity is determined by the steric bulk of catalyst substituents (II, Scheme 1). ${ }^{4}$ Opposite product stereochemistry is predicted in the two models for the reaction of enamines with $\mathrm{X}=\mathrm{Y}$ electrophiles.

The results we present in this work lead to the development of a general concept for selectivity in asymmetric aminocatalysis that incorporates additional factors not considered in the transition state models shown in Scheme 1. We document two examples of reactions in which stable, equilibrated intermediate species appear in the catalytic cycle downstream from the stereogenic center-forming step. This allows us to propose a selectivity paradigm invoking Curtin-Hammett ${ }^{5}$ control, modulated by the relative stability of diastereomeric intermediate species. The concept is discussed in the context of the conjugate addition of linear aldehydes to nitro-olefins and the $\alpha$-chlorination of aldehydes, both catalyzed by pyrrolidine-based systems that are thought to follow the stereochemical model II. The general implications of such a selectivity paradigm in asymmetric organocatalysis both for mechanistic understanding and for catalyst and reaction design are discussed.

\section{RESULTS AND DISCUSSION}

Conjugate Addition. Since their introduction by Hayashi ${ }^{6}$ and by Jorgensen, ${ }^{7}$ diarylprolinol ethers such as $\mathbf{3}$ have enjoyed spectacular success in a variety of enamine- and iminium-based organocatalytic transformations. ${ }^{4}$ Most notably, they figure prominently in cascade sequences where Michael additions typically appear as the first transformation in combinations such as En-Im-En consecutive cycles. ${ }^{8}$ In addition, the conjugate addition of linear aldehydes to nitro-olefins (Scheme 2, top) has become a benchmark reaction for probing the efficiency and selectivity of new aminocatalysts.

While model II offers a rationale for the sense of the stereochemical outcome of the attack of the enamine on electrophiles such as $\mathbf{2 a}$, several features of the reactions shown in Scheme 2 raise questions that are difficult to rationalize solely by the proposed steric arguments. First, reactions of linear aldehydes

Received: January 13, 2012

Published: March 27, 2012 
Scheme 2. Relative Reactivity and Selectivity of $1 \mathrm{a}$ and $1 \mathrm{~b}$ in Reactions with 2 a Catalyzed by $3^{11}$

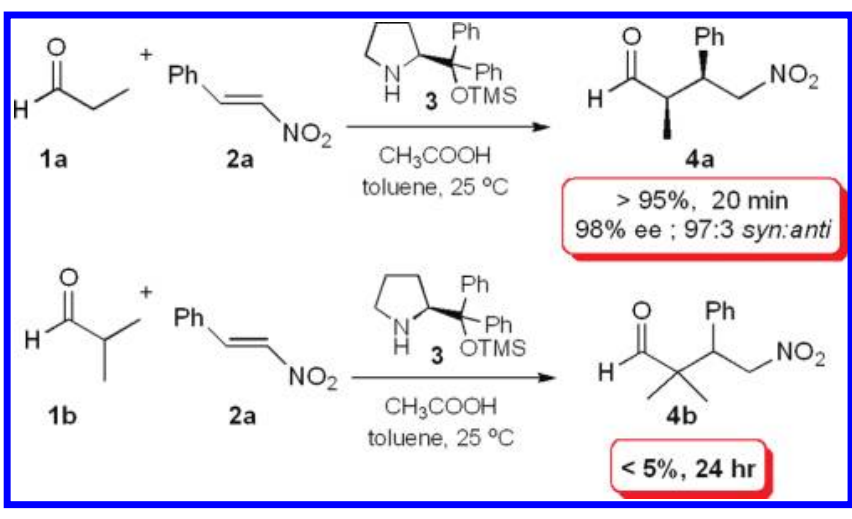

with nitro-olefins proceed not only with high enantioselectivity but also with a high level of facial selectivity with respect to the nitro-olefin electrophile, a feature that is not readily explained by model II. Selectivity typically follows Seebach's topological rule, and it has been conceded that the actual mechanism may be more complicated. ${ }^{9}$ Facial selectivity in this reaction using primary amine thiourea catalysts has been explained by invoking enzyme-like effects of approximation and hydrogen bonding of the nitroalkene to the catalyst, ${ }^{10}$ but such effects are not applicable to catalyst systems following model II.

Second, while the reaction of $\mathbf{2 a}$ with $\mathbf{1 a}$ is extremely efficient, reaction with $\mathbf{1 b}$ (Scheme 2, bottom) is extremely sluggish. Enamine formation between $\mathbf{3}$ and either $\mathbf{1 a}$ or $\mathbf{1 b}$ occurs in minutes under these conditions, ${ }^{11}$ and near quantitative conversion to $4 \mathrm{a}$ occurs on the order of minutes, but only minimal formation of product $\mathbf{4 b}$ is observed even after $24 \mathrm{~h}$. This stark difference in reactivity is difficult to explain solely by the increase in steric bulk afforded by exchange of $\mathrm{R}^{2}=\mathrm{H}$ for $\mathrm{R}^{2}=\mathrm{CH}_{3}$ in an enamine reacting with an $\mathrm{X}=\mathrm{Y}$ electrophile as envisioned in model II.

We uncovered a further mechanistic puzzle in studies of deuterium isotope effects in the reaction of propanal 1a with nitrostyrene $2 \mathrm{a}$ catalyzed by 3 . Figure 1 shows that kinetic

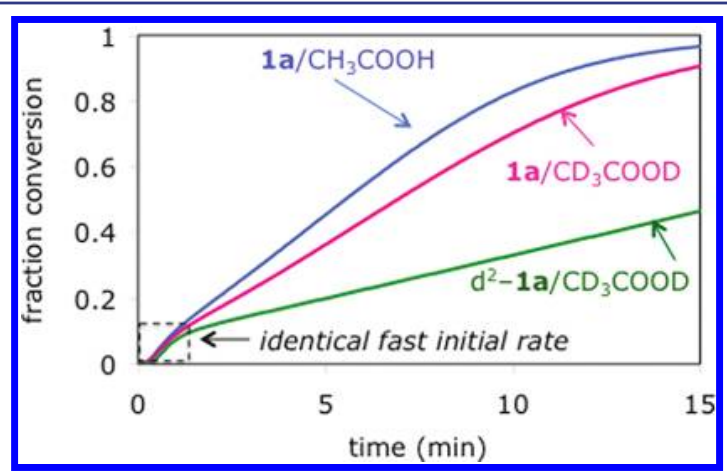

Figure 1. Deuterium isotope effects monitored as fraction conversion vs time for the reaction of $1 \mathrm{a}$ with $2 \mathrm{a}$ catalyzed by 3 in toluene at $25^{\circ} \mathrm{C}$ in the presence of normal and deuterated acetic acid and normal and deuterated 1a. Reaction conditions: $[\mathbf{1 a}]_{0}$ and $\left[\mathrm{d}^{2}-\mathbf{1 a}\right]_{0}=1.2 \mathrm{M}$; $[2 \mathrm{a}]_{0}=1.0 \mathrm{M} ;[3]=0.1 \mathrm{M} ;\left[\mathrm{CH}_{3} \mathrm{COOH}\right]$ or $\left[\mathrm{CD}_{3} \mathrm{COOD}\right]=0.1 \mathrm{M}$; $\left[\mathrm{H}_{2} \mathrm{O}\right]$ or $\left[\mathrm{D}_{2} \mathrm{O}\right]=0.5 \mathrm{M}^{11}$

isotope studies employing deuterated acetic acid gave a normal isotope effect, albeit of small magnitude, with $k_{\mathrm{H}} / k_{\mathrm{D}}=1.28$. Both our work ${ }^{12}$ and that of Hayashi and Seebach ${ }^{13}$ have quantified rate acceleration upon addition of acid in this reaction, in accordance with many reports showing that addition of acid leads to higher yields. Surprisingly, as also shown in Figure 1, employing the deuterated substrate $\mathrm{d}^{2}-1$ a (deuterated at the $\alpha$-H positions) together with $\mathrm{CD}_{3} \mathrm{COOD}$ gave a much stronger isotope effect, for a cumulative $k_{\mathrm{H}} / k_{\mathrm{D}}=3.25$. Although enamine formation with catalyst 3 is accelerated by acid, this step is ruled out as rate-determining in the reactions of Scheme 2 because of the observation of zero-order kinetics in [1a]. Thus observation of such an isotope effect in a substrate that undergoes non-rate-determining deprotonation is difficult to reconcile with a reaction known to be accelerated by acid. In addition, all reactions regardless of deuterium content exhibit identical rapid initial rates, accounting, as previously reported, for ca. 1 turnover of the catalyst prior to a transition to a slower regime of overall zero-order kinetics. ${ }^{12}$

NMR spectroscopy provides further clues concerning the role of protonation and deprotonation of intermediates. Our recent studies ${ }^{12}$ of this reaction and those of Hayashi and Seebach ${ }^{13}$ using catalyst 3 identified stable cyclobutane species 5 (Scheme 3) existing as a single diastereomer as the resting

Scheme 3. Reversible Formation of Cyclobutane $5^{12}$

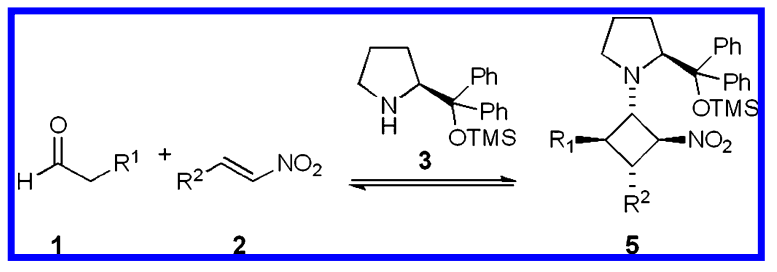

state in the system, resulting from reversible attack of the enamine on the nitro-olefin. Further NOESY experiments carried out on the cyclobutane species $5 \mathrm{a}\left(\mathrm{R}^{1}=\mathrm{CH}_{3} ; \mathrm{R}^{2}=\mathrm{Ph}\right)$ prepared from 1a, $\mathbf{2} \mathrm{a}$, an excess of $\mathbf{3}$, and molecular sieves (to suppress hydrolysis to product $4 \mathbf{a}$ ) revealed EXSY cross-peaks for a minor species $\mathbf{6}$ in equilibrium with the cyclobutane (Figure 2). The same species was detected, albeit to a slightly

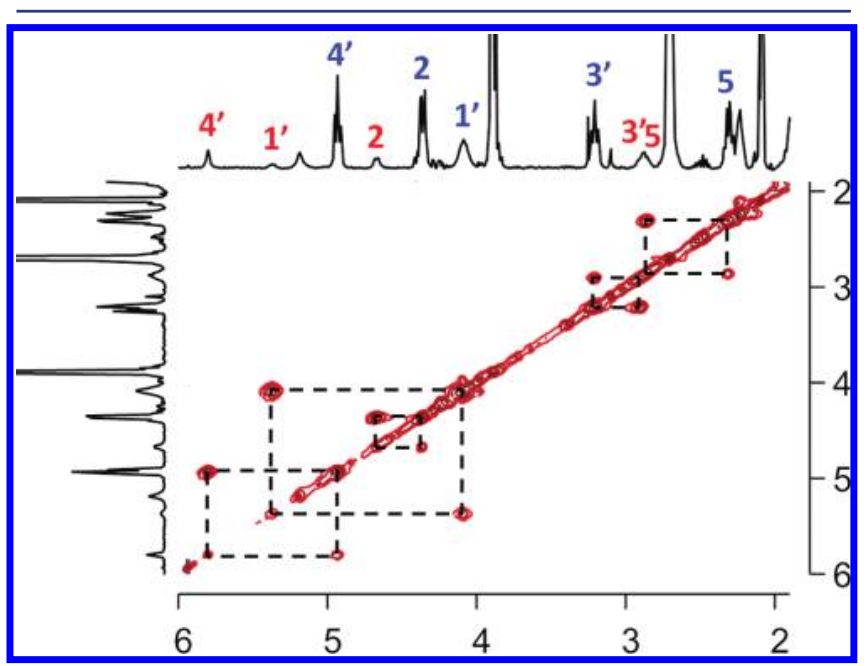

Figure 2. NOESY experiment of 5a identifying EXSY cross-peaks for new species 6 as shown in Scheme 4. Peak numbers refer to carbon atoms of 5 a (blue) and 6 (red) in Scheme $4 .{ }^{11}$

lesser extent, during the catalytic reaction under standard reaction conditions. ${ }^{11}$ Importantly, no EXSY cross-peaks were detected for the stable cyclobutane species $\mathbf{5 b}$ derived from the $\alpha$-branched aldehyde $\mathbf{1 b}$ with a methyl group in place of the proton at the $2^{\prime}$ position (Scheme 4$) .{ }^{11}$ 
Scheme 4. Assignment of Intermediate Species 6 from EXSY Shifts ${ }^{11}$

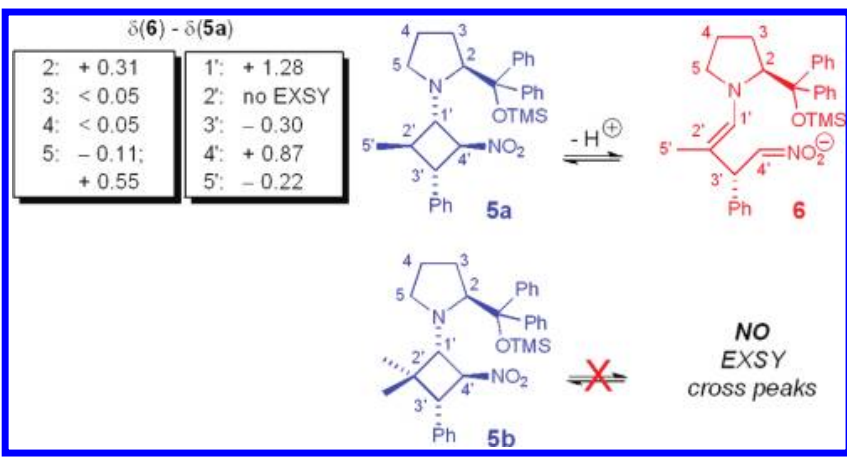

The observed EXSY cross-peaks allow a comparison of the shifts of the signals for this new species to those of the cyclobutane 5a. ${ }^{11}$ No EXSY correlation with the new species is observed for the proton at $2^{\prime}$ on $\mathbf{5 a}$, suggesting that 6 lacks this proton. In addition, the protons attached to the $1^{\prime}$ and $4^{\prime}$ carbon atoms of $5 \mathbf{a}$ are the most affected in the exchange experiment. This leads to the proposal for the identity of this new minor species as $\mathbf{6}$ shown in Scheme 4, where the $1^{\prime}$ and $2^{\prime}$ carbon atoms change in hybridization from $\mathrm{sp}^{3}$ to $\mathrm{sp}^{2}$ upon formation of the enamine nitronate 6 after deprotonation at 2 '. Such a species cannot be formed from cyclobutane $\mathbf{5 b}$, which explains the lack of EXSY cross-peaks in this case. Although 6 cannot be isolated, the EXSY correlation provides strong support for its intermediacy between 5 a and 7, both of which species have been characterized and reported previously by us. ${ }^{12}$

The significance of the presence (or lack thereof) of a proton at the 2 ' position of cyclobutane 5 extends to the catalytic and kinetic isotope results. While it has been suggested that this species is a "parasitic" off-cycle reservoir, we may rationalize the isotope effects of both $\mathrm{CD}_{3} \mathrm{COOD}$ and $\mathrm{d}^{2}-1 \mathrm{a}$ by proposing that deprotonation of the resting state $\mathbf{5 a}$ to form the minor species $\mathbf{6}$ occurs on the catalytic cycle, followed by protonation to give the product enamine, which is formed exclusively as E-7, as shown in Scheme 5.

Scheme 5. Modified Catalytic Cycle Proceeding through 5a, 6 , and $7^{a}$

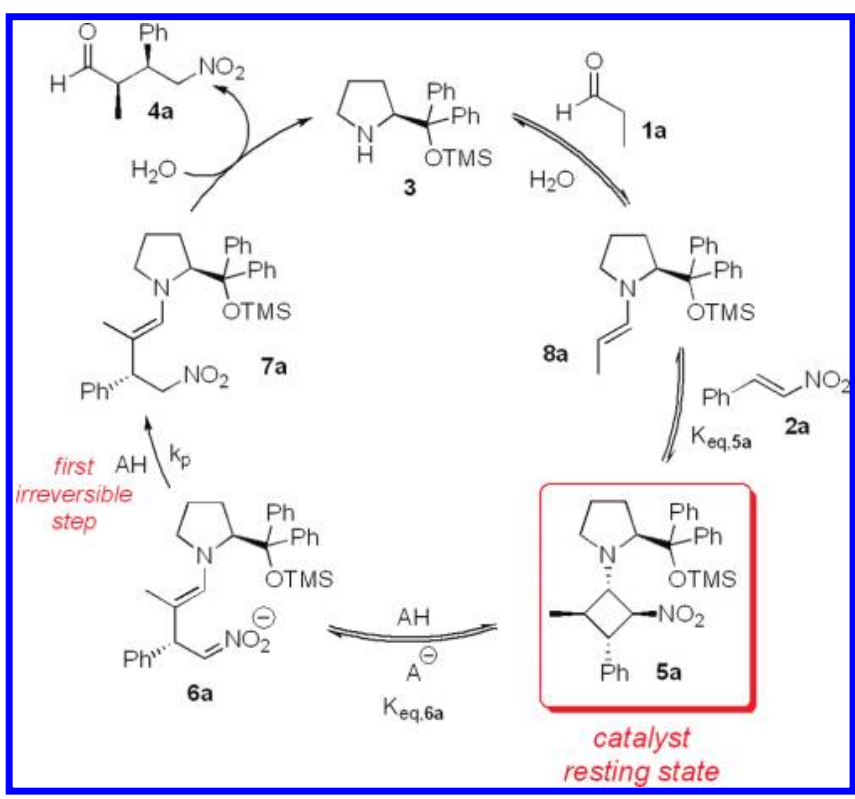

${ }^{a}$ All catalytic species in the cycle have been observed experimentally.
All catalytic species shown in the modified catalytic cycle presented in Scheme 5 have been observed experimentally. Some of the steps shown may represent sequences of elementary reactions combined into one kinetically meaningful step. ${ }^{14}$ As we have shown previously, the fast initial rate (Figure 1, dashed box) represents saturation of species $\mathbf{5 a}$ in steps that rapidly become equilibrated, explaining the insensitivity of initial rate to deuterium isotope effects. The subsequent deprotonation and protonation steps shown in Scheme 5 both contribute to the overall observed kinetics of the zero-order regime that dominates the remainder of the reaction, and the isotope effect $\left(k^{\mathrm{H}}\right)_{\text {obs }} /\left(k^{\mathrm{D}}\right)_{\text {obs }}$ will exhibit a complex dependence on the elementary rate constants associated with these steps. ${ }^{15}$

The proposal of a highly selective reaction Pathway through enamine 7 may at first appear to be counterintuitive, given that this step destroys the stereocenter formed in the addition step. However, our observation of enamine E-7 exclusively, and the fact that the syn:anti product ratio remains constant during reaction turnover, are in accord with the suggestion that a stereospecific relationship exists between E-7 and the major syn product. We recently demonstrated stereospecific enamine formation between 3 and 2-phenyl propionaldehyde. ${ }^{16}$ EXSY experiments carried out on reaction of the thermodynamic syn:anti product mixture with 3 demonstrate that E-7 correlates preferentially with the syn adduct, as shown in Figure $3 .^{11}$

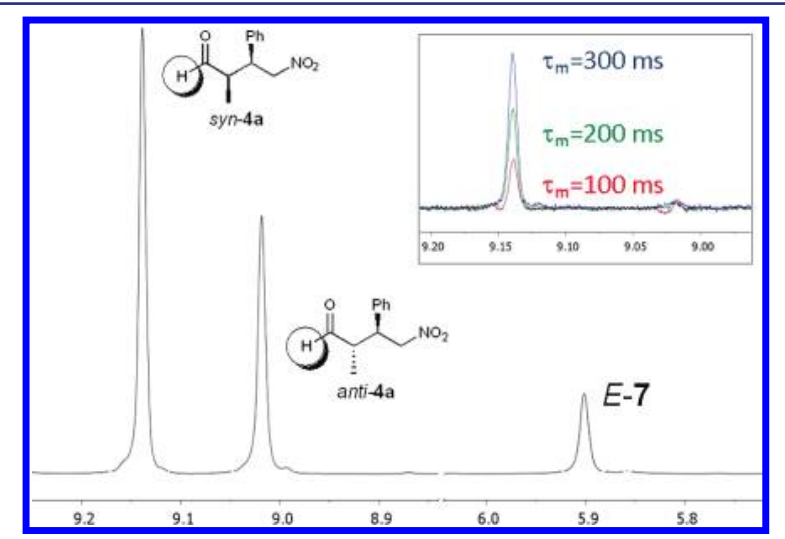

Figure 3. ${ }^{1} \mathrm{H}$ NMR spectrum of an equilibrated mixture of $4 \mathrm{a}(0.87 \mathrm{M}$, syn:anti $=60: 40)$ with $3(0.36 \mathrm{M})$ and acetic acid $(0.66 \mathrm{M})$ forming $E-7$ at $25{ }^{\circ} \mathrm{C}$. Inset: EXSY peaks from irradiation of $E-7$ (olefinic proton) using a 1-D GOESY sequence (600 MHz field) at different mixing times $\tau$ as shown.

We have shown that the syn:anti product ratio erodes when product 4a remains in contact with the catalyst for an extended period after reaction turnover is complete and the free catalyst is no longer sequestered as 5 a (Scheme 6). Figure 4 shows that,

Scheme 6. Reversible Enamine Formation between 3 and syn-4a and anti-4a

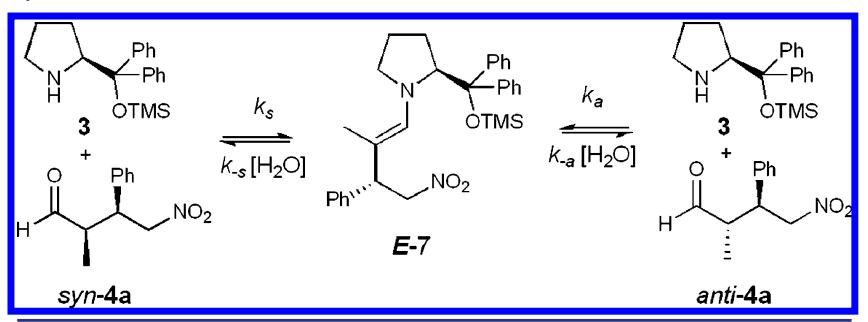

when the product with syn:anti $=93: 7$ is mixed with 3 , a low steady-state concentration of enamine $E-7$ is rapidly established, 


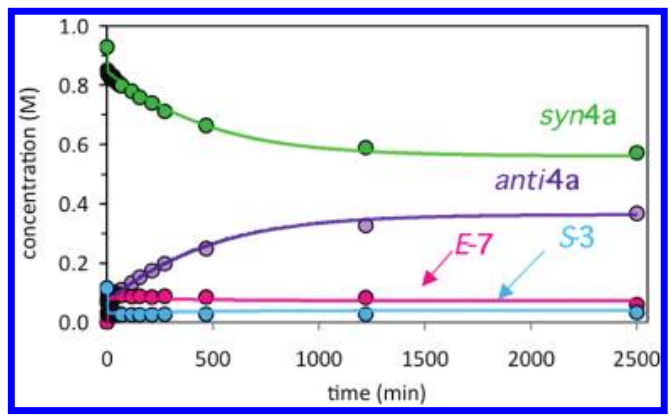

Figure 4. Temporal profiles of the reaction of $\mathbf{4 a}$ with 3 monitored by NMR spectroscopy. $[4 \mathbf{a}]_{0}=1.0 \mathrm{M}($ syn:anti $=93: 7) ;[3]_{0}=0.115 \mathrm{M}$.

and equilibration between syn-4a and anti-4a continues until the thermodynamic ratio of ca. $60: 40$ is reached. ${ }^{17}$ The equilibrium constants for enamine formation from syn and anti, $K_{\text {eq, }}$ and $K_{\text {eq,A }}$ may be estimated from the final concentrations in Figure 4, as shown in Scheme 6 and eq 1.

$$
\begin{aligned}
& K_{\mathrm{eq}, \mathrm{S}}=\frac{k_{\mathrm{s}}}{k_{-\mathrm{s}}\left[\mathrm{H}_{2} \mathrm{O}\right]}=\frac{[E-7]_{\mathrm{eq}}}{[s y n-\mathbf{4 a}]_{\mathrm{eq}}[\mathbf{3}]_{\mathrm{eq}}}=3.2 \\
& K_{\mathrm{eq}, \mathrm{A}}=\frac{k_{\mathrm{a}}}{k_{-\mathrm{a}}\left[\mathrm{H}_{2} \mathrm{O}\right]}=\frac{[E-7]_{\mathrm{eq}}}{[\text { anti-4a }]_{\mathrm{eq}}[\mathbf{3}]_{\mathrm{eq}}}=4.9
\end{aligned}
$$

Non-stereoselective protonation of E-7 would exhibit identical rates for forming syn-4a and anti-4a, or a selectivity ratio $s=$ $k_{-s} / k_{-a}=1$. However, as shown in Figure 5, the experimentally

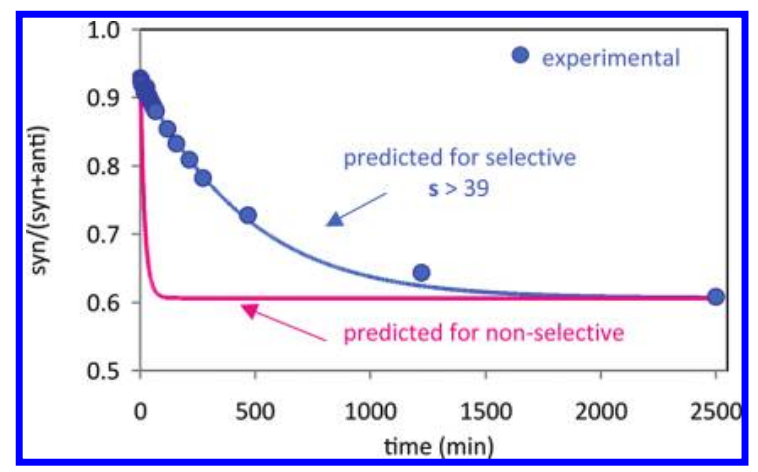

Figure 5. Experimental and calculated $s y n /(s y n+a n t i)$ for the data shown in Figure 4. For nonselective enamine protonation, $k_{-\mathrm{s}}=k_{-\mathrm{a}}$. Experimental data fit to $k_{-s} / k_{-a} \geq 39 .^{11,18}$

observed temporal change in the syn:anti ratio cannot be accurately described for non-selective enamine protonation. Kinetic modeling $^{11,18}$ of the process shown in Scheme 6 accommodates the experimental data with a selectivity ratio of $s>39$, revealing that enamine protonation is a highly selective process. Since protonation of $\mathbf{6}$ is an irreversible step on the catalytic cycle, the stereochemistry at C-2' that was set in the addition step in Scheme 5 is preserved in the initial formation of product 4 a through stereoselective product enamine formation and protonation.

The modified cycle proposed in Scheme 5 allows us to address the features of the reactions of Scheme 2 that were difficult to explain solely by the steric model II. First, the route through cyclobutane 5a provides a rationalization of the high facial selectivity observed with regard to nitrostyrene, attributing this to the high stability of the single diastereomer 5a and to the stereospecificity of its reaction, rather than calling simply on specificity in the approach of the nitro-olefin to the enamine. The enhanced stereocontrol afforded by the reaction pathway through the stable species 5 a provides an alternative to Seebach's acyclic synclinal model ${ }^{9}$ invoking a transition state with favorable electrostatic interactions between the nitrogen of the enamine $\mathbf{8}$ and the nitro group of $\mathbf{2 a}$.

Scheme 5 also provides an explanation of the second curious feature noted earlier concerning the near-inertness of $\alpha$ branched aldehydes such as $\mathbf{1} \mathbf{b}$ in the conjugate addition with nitrostyrene $2 \mathrm{a}$. This may be rationalized by the fact that these reactions cannot proceed by the newly proposed pathway through species 6 and 7; the lack of a proton at the $2^{\prime}$ position precludes the possibility of formation of enamine 7 from $\mathbf{5 b}$. As in the case of linear aldehydes, cyclobutane $\mathbf{5 b}$ is formed rapidly and remains the catalyst resting state; however, in the reaction of $\mathbf{1 b}$, cyclobutane $\mathbf{5 b}$ exists as a true off-cycle reservoir that sequesters most of the catalyst. Therefore, the concentration active on-cycle species is vanishingly small, resulting in a severe suppression of the rate of turnover of $\mathbf{1 b}$.

The role of the cyclobutane intermediate 5a in the catalytic cycle described in Scheme 5 has implications for the proposed mechanistic models of Scheme 1. In any competitive reaction network, selectivity is determined by $\Delta \Delta G^{\ddagger}$, the difference in energies of the relevant transition states. Our results suggest that the transition state relevant for the network of Scheme 5 lies subsequent to the step in which the stereogenic center is formed, providing a counterpoint to the classic transition-state model II. Figure 6 compares model II (Pathway A) to the novel proposed mechanistic pathway through 5a (Pathway B). For this theoretical comparison, the two pathways are shown as exhibiting the same $\Delta \Delta G^{\ddagger}$. Numbered intermediates are based in Scheme 5. Figure $6 \mathrm{~b}$ shows parallel networks for products $4 \mathrm{a}$ and $4 \mathbf{a}^{\prime}$, which are enantiomeric at the C-2 stereocenter formed in the addition step.

It is widely assumed in enamine-based organocatalysis for both models I and II shown in Scheme 1 that product enantioselectivity is determined as shown in Pathway A (Figure 6a). Product enantiomeric ratio (er) in this classic case is given by the ratio of rate constants for an irreversible reaction step between enamine 8a and electrophile $\mathbf{2 a}$, or $k_{2} / k_{2}{ }^{\prime}$ (Figure $6 \mathrm{c}$ ).

If, however, stable intermediates such as $\mathbf{5 a}$ are reversibly formed on the cycle subsequent to the stereogenic centerforming step-as in Scheme 5 and Pathway B in Figure 6-all preceding intermediates appearing in the catalytic cycle become equilibrated, because $\mathbf{5}$ a serves as the resting state, or what may be termed the "hold-up" point in the cycle. In Pathway B the relevant transition state for determining product er is not the stereogenic center-forming step shown in model II; rather, product er depends on two separate factors revealed in the equation in Figure 6c: (i) a kinetic component given by the relative rate constants for the first irreversible step and (ii) $a$ thermodynamic component given by the relative equilibrium constants for all the equilibrated diastereomeric intermediates appearing prior to the first irreversible step in the mirror image networks. Thus, Figure 6a shows that the $\Delta \Delta G^{\ddagger}$ value determining product selectivity via Pathway $\mathrm{B}$ derives from a combination of the relative heights of the transition states for the first irreversible step and the relative depths of the energy wells for the preceding intermediates.

Selectivity in Pathway B can differ from that in Pathway A because the relative rates of electrophile attack by the common enamine $\mathbf{8}\left(k_{2} / k_{2}{ }^{\prime}\right)$ may not necessarily correlate with the relative stability of species formed after that attack. ${ }^{19}$ Indeed, it may 


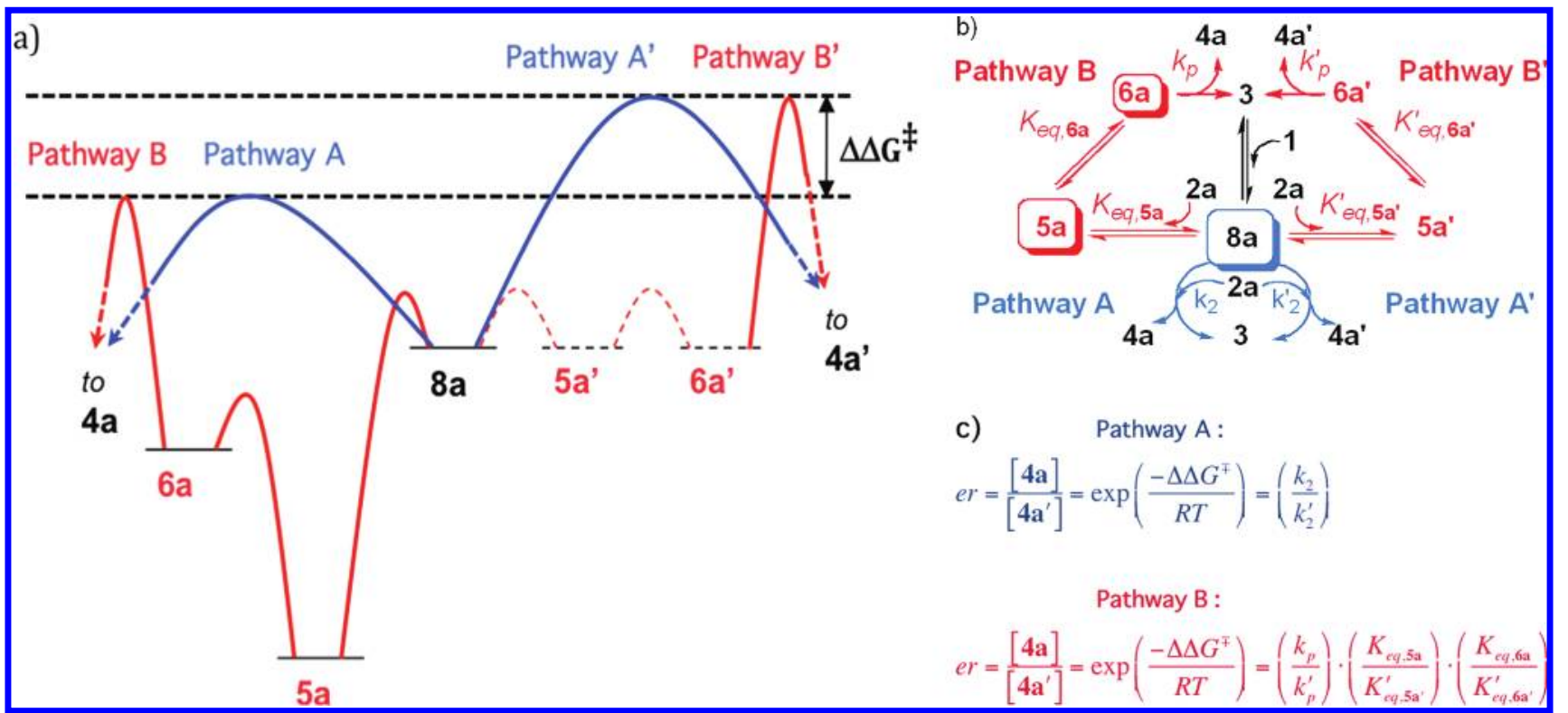

Figure 6. Comparison of proposed mechanistic pathways for the two enantiomeric cycles of the reaction of Scheme 5, with compound numbering as in Scheme 5. Pathway A/A' represents selectivity as would be determined according to model II by the transition state for reaction between $\mathbf{2 a}$ and $\mathbf{8 a}$. Pathway B/B' represents the novel pathway proposed in Scheme 5, where selectivity is determined by the relative stabilities and activities of downstream intermediates. (a) Reaction pathway qualitatively described by the energy diagram from the point of bifurcation at addition of the electrophile to the enamine. Structures for experimentally observed species 5a, 6a, and $\mathbf{8 a}$ are shown. Dashed lines are given for Pathway B' where no species have been experimentally observed. (b) Reaction pathway described by rate and equilibrium steps, with proposed rate-determining species for each pathway highlighted in boxes. Only kinetically meaningful species are included. (c) Mathematical description of the enantiomeric ratio (er) for each pathway, equating the transition-state energy difference to the appropriate relationship to the kinetic and equilibrium constants.

be seen from the equation in Figure $6 \mathrm{c}$ that a highly selective reaction could result from Pathway $B$ even if the attack of the enamine on the electrophile is itself unselective. ${ }^{19}$

Pathway B introduces an intriguing Curtin-Hammett scenario for stereocontrol. The Curtin-Hammett principle, invoked for cases where rapidly equilibrating conformers or intermediate species exist on parallel pathways to reaction products, states that the product ratio is controlled only by the difference in standard free energies $\left(\Delta \Delta G^{\ddagger}\right)$ derived from the respective transition states and cannot be determined a priori solely from knowledge of the relative concentrations of intermediate species. However, the IUPAC definition acknowledges that the $\Delta \Delta G^{\ddagger}$ value obtained under Curtin-Hammett conditions embodies both kinetic and thermodynamic components of selectivity, as we demonstrated in Figure 6 for Pathway B: product composition is "formally related to the relative concentrations" of intermediates and to "the respective rate constants of their reactions".

A pioneering example of Curtin-Hammett selectivity control in asymmetric catalysis was revealed by Landis and Halpern's studies of asymmetric hydrogenation of enamides catalyzed by chiral $\mathrm{Rh}$ phosphines under low $\mathrm{H}_{2}$ pressure. ${ }^{21,22}$ Enantioselectivity was ultimately governed by the ratio of rate constants for the irreversible oxidative addition of hydrogen to Rh-enamide complexes, although the major product was formed through the pathway of the less stable, minor intermediate. In that "major-minor" case, the sense of the contribution of the thermodynamic component was overridden by that of the kinetic component of the Curtin-Hammett relation for product ratio. Conversely, it is also possible that higher intermediate stability can outweigh lower reactivity as the determining factor in competitive reactions in a scenario that has been termed "monopolizing kinetics". ${ }^{23}$ In the present case, the thermodynamic component is found to dictate selectivity.
Another noteworthy distinction in the example presented here compared to the Landis-Halpern case is the role of an explicit reversible connectivity between the enantiomeric cycles that occurs subsequent to the step in which the stereogenic center is initially formed. Our example also differs from examples of stereodivergent networks where enantiodifferentiation occurs after the first irreversible step, as demonstrated in several cases including Schiff base (metal)-catalyzed epoxidations and aziridinations ${ }^{24}$ and $\operatorname{Pd}$ (binap)-catalyzed arylation of dihydrofuran. ${ }^{25}$ The selectivity scenario illustrated in Figure 6 is, to the best of our knowledge, revealed here for the first time in organocatalysis.

In all of these examples, mechanistic understanding as well as reaction improvement ultimately relies on an accurate assessment of the step in the cycle representing the relevant transition state for stereocontrol. In the present example, examination of the energy diagram of Figure $6 a$, the network of Figure $6 b$, and the equation for er shown in Figure $6 \mathrm{c}$ reveals a key consequence of this scenario, which is that a network obeying Pathway B affords a number of different potential points in the cycle where stereocontrol may be induced. This concept may have important general implications for catalyst and reaction design. Rather than placing an exclusive focus on the transition states of the stereogenic center-forming step, strategies for the discovery and design of efficient catalyst/substrate combinations that would conventionally be assumed to follow the steric model II might benefit from consideration of means for optimization of the relative activity or stability of downstream intermediates, such as $\mathbf{5 a} / \mathbf{5} \mathbf{a}^{\mathbf{2}}$, as a design tool to enhance er.

$\boldsymbol{\alpha}$-Chlorination. The first highly enantioselective, direct $\alpha$ chlorination of aldehydes was reported by MacMillan and coworkers $^{27}$ using imidazolidinones with acid co-catalysts. A protonmediated cyclic transition state corresponding to our Pathway A was proposed as the stereo-defining step in that work. Jorgensen ${ }^{28}$ 
reported highly enantioselective chlorination using 2,5-diphenylpyrrolidine 10, proposing that the reaction proceeds via an unusual initial $N$-chlorination followed by a 1,3-sigmatropic shift of the chlorine atom to the enamine carbon atom. Interestingly, $\alpha$-chlorination using diarylprolinol ethers 3 or 9 has not been reported (Scheme 7), although these catalysts undergo selective $\alpha$-fluorination and $\alpha$-bromination. ${ }^{4,7}$

Scheme 7. $\alpha$-Chlorination of Aldehydes with Different Catalysts and Chlorinating Agents

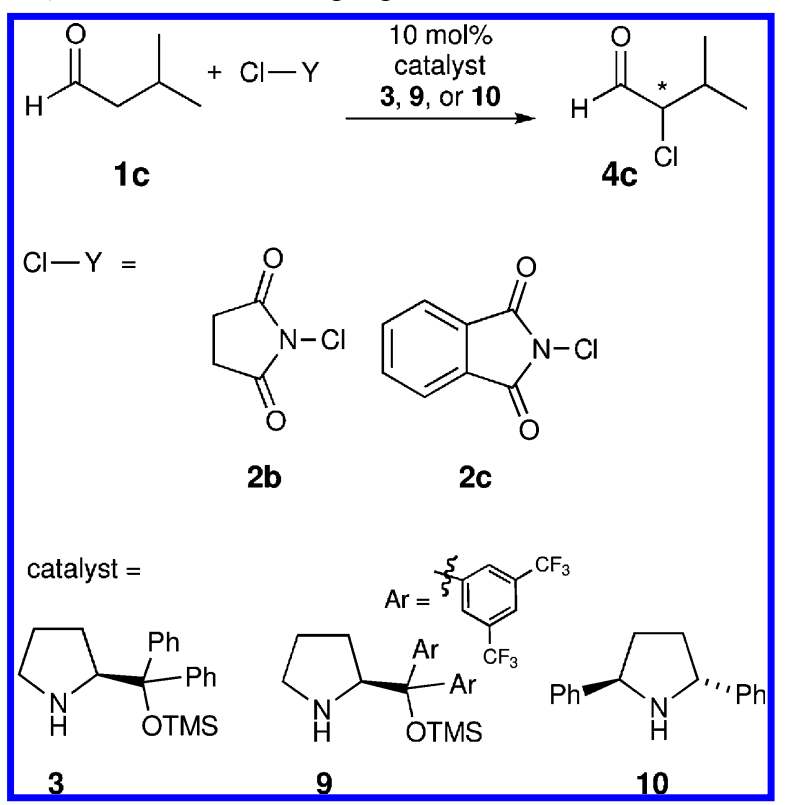

We examined the kinetic profile of the reaction of Scheme 7 using catalyst $\mathbf{3}$ and chlorinating sources $\mathbf{2 b}$ and $\mathbf{2 c}$, monitoring conversion by reaction calorimetry. Figure 7 shows that the

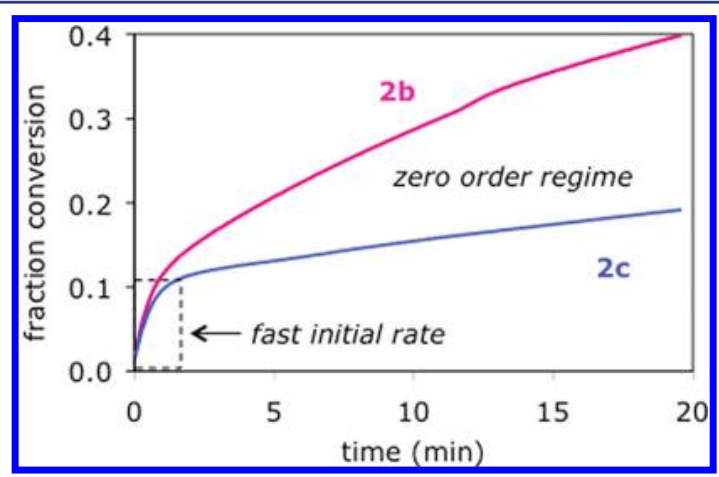

Figure 7. Conversion vs time for the reaction of Scheme 6 with $\mathbf{2 b}$ and $2 c(0.63 \mathrm{M})$ and $1 \mathrm{c}(0.48 \mathrm{M})$ using $10 \mathrm{~mol} \%$ catalyst 3 and $2 \mathrm{~mol} \%$ $\mathrm{CH}_{3} \mathrm{COOH}$ at $-11.4{ }^{\circ} \mathrm{C}$ in $\mathrm{CHCl}_{3} .{ }^{11}$

kinetic profile exhibits features that closely resemble those observed for the conjugate addition of aldehydes to nitrostyrene with this catalyst. A rapid initial rate corresponding to $\mathrm{ca}$. one turnover of the catalyst was followed by a slower zero-order regime, demonstrating that the reaction does not depend on the concentration of either of the two reactants. Curiously, however, Figure 7 also shows that, although the rate in the second regime is insensitive to concentrations, its absolute magnitude is influenced by the nature of the chlorinating reagent, with the bulkier $\mathrm{N}$-chlorophthalimide $2 \mathrm{c}$ being less reactive.
In analogy with our results for the conjugate addition to nitrostyrene using 3, this kinetic profile suggests the rapid buildup within the cycle of a stable intermediate species that contains both substrates. The rate-determining step occurs downstream from this resting state, which lies after the step in which the electrophile $\mathrm{X}-\mathrm{Y}$ is added to form the stereogenic center.

Variable-temperature NMR spectroscopic studies of the interaction of $\mathbf{1 c}$ with $\mathrm{N}$-chlorosuccinimide $\mathbf{2 b}$ and catalyst $\mathbf{3}$ were carried out to probe the identity of the intermediate species implied from the kinetic data. Observation of a single peak at room temperature that resolves into two peaks below ca. $-30{ }^{\circ} \mathrm{C}$, as shown in Figure 8 (top), suggests a rapid and

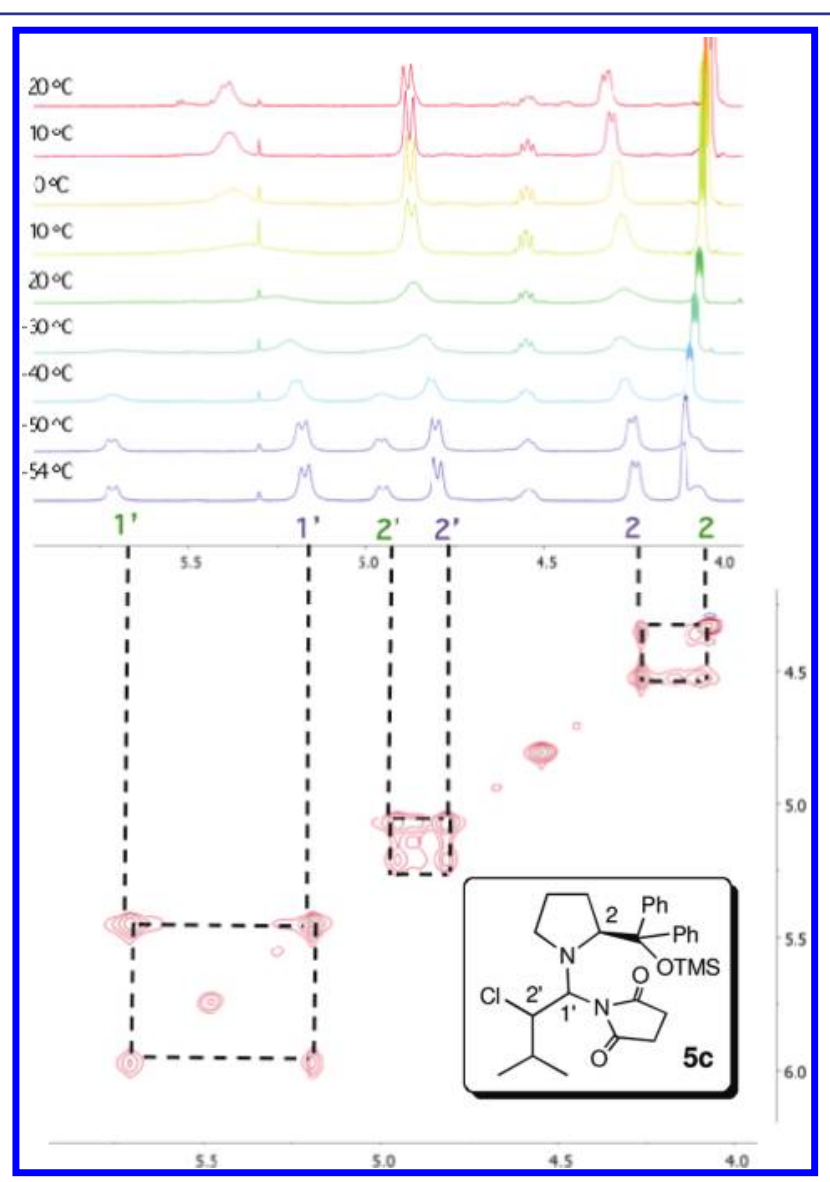

Figure 8. (Top) Variable-temperature ${ }^{1} \mathrm{H}$ NMR spectra of $1 \mathbf{c}(0.65$ $\mathrm{M}), 2 \mathbf{b}(0.5 \mathrm{M})$, and $3(0.1 \mathrm{M})$ in $\mathrm{CDCl}_{3}$ showing an apparent single resting state at $20^{\circ} \mathrm{C}$ that splits into two diastereomers below $-30{ }^{\circ} \mathrm{C}$. (Bottom) EXSY cross-peaks reveal the connectivity of the two diastereomers of $\mathbf{5 c}$ existing at room temperature in a rapid equilibrium.

reversible equilibrium between two diastereomers, which is confirmed by EXSY experiments as shown in Figure 8 (bottom), allowing assignment of aminal $\mathbf{5 c}$ analogous to a species reported by Jorgensen using pyrrolidine. ${ }^{28 \mathrm{~b}}$ NMR studies using catalysts 9 and 10 identified analogous aminal diastereomers. In none of these examples was any evidence observed for the $N$-chlorinated intermediate proposed by Jorgensen. ${ }^{28 \mathrm{~b}}$ Taken together, the kinetic and spectroscopic results suggest that the rapid initial rate corresponds to the buildup of $\mathbf{5 c}$ as the resting state in the catalytic system.

Table 1 shows the ratio of the two NMR peaks for diastereomeric species $\mathbf{5 c}$ formed from the interaction of $\mathbf{1 c}$ with $\mathbf{2 b}$ or $2 \mathrm{c}$ and the catalysts $3, \mathbf{9}$, and $\mathbf{1 0}$. The ratio of diastereomers 
Table 1. Diastereomeric Ratios (dr) for Species 5c Identified by NMR and Correlation with the Stereochemical Outcome of the Catalytic Reaction ${ }^{11}$

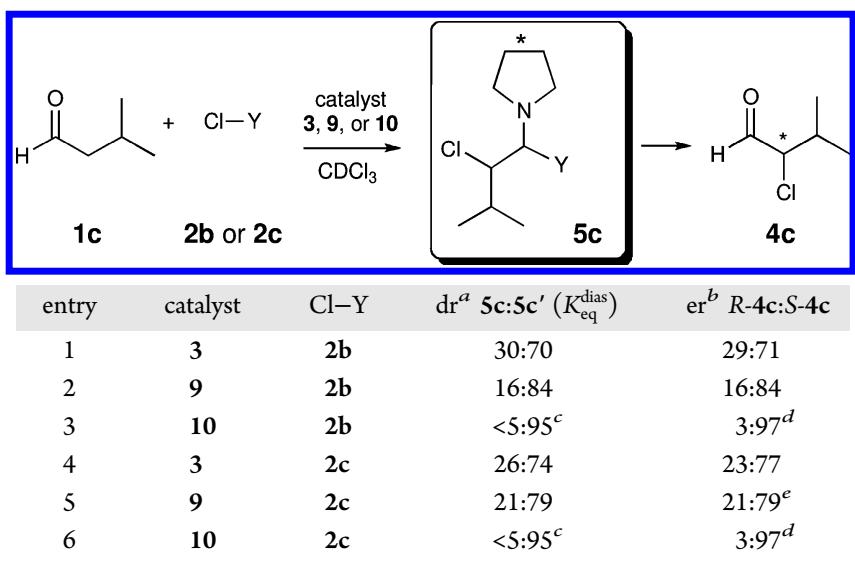

${ }^{a} K_{\mathrm{eq}}{ }_{\text {dias }}=[$ syn-5c $] /[$ anti-5c $]$ or $\left[\right.$ syn-5 $\left.\mathbf{c}^{\prime}\right] /\left[\right.$ anti-5 $\left.\mathbf{c}^{\prime}\right]$, determined from NMR spectroscopy at $-54{ }^{\circ} \mathrm{C}$. ${ }^{b}$ Determined by chiral GC. ${ }^{c}$ Minor diastereomer not detected. ${ }^{d}$ From ref $28 \mathrm{~b} .{ }^{e} \mathrm{Ca}$. $5 \%$ conversion.

depends on the catalyst employed, ranging from 30:70 for 3 with $\mathbf{2 b}$ to the case of catalyst $\mathbf{1 0}$, where a single diastereomer is observed with either electrophile. Strikingly, Table 1 also reveals that an excellent correlation exists between the ratio of diastereomeric species $\mathbf{5 c}$ and the er of the reaction product $4 \mathrm{c}$ for all catalysts and both electrophiles.

The results of Table 1 imply that the diastereomeric species 5c are directly involved in catalyst turnover, rather than existing as parasitic off-cycle reservoirs. In support of this proposal, consideration of species $\mathbf{5 c}$ as the resting state and invoking rate-determining elimination of the leaving group $\mathrm{Y}$ from this species helps to explain the seemingly contradictory observations of overall zero-order kinetics and a difference in reactivity for different chlorinating reagents.

The close relationship between the relative concentrations of the diastereomers of $\mathbf{5 c}$ and the er of product $4 \mathrm{c}$ requires careful analysis of potential mechanistic pathways that might involve these species. The atom connectivity identified by our NMR studies allows four possible diastereomers of 5c, consisting of two sets of syn:anti pairs formed from attack at opposite faces of the enamine. If addition of chloride to the enamine is considered to be irreversible, the observed equilibration of the diastereomers of $5 \mathrm{c}$ could occur via reversible dissociation of the leaving group $\mathrm{Y}(\mathrm{Y}=$ succinimide or phthalimide), as shown in Scheme 8. This scheme shows the conventionally proposed catalytic route within the dotted lines, where the product is derived directly from the iminium ion species formed upon addition of $\mathrm{Cl}$, analogous to a Pathway A scenario in our previous example. The scheme also proposes a catalytic route arising from diastereomeric intermediates formed from this iminium ion. This route exhibits some features of our previously described Pathway B, with kinetically meaningful intermediates being formed on-cycle and equilibrating downstream from the explicit stereogenic center-forming step.

In the conventional route, stereocontrol is set in the $\mathrm{Cl}$ addition step to enamine $8 \mathrm{c}$ forming the iminium ion $11 \mathrm{c}$ (or $\left.11 c^{\prime}\right)$, which directly undergoes hydrolysis to form the product. In this scenario the diastereomers $\mathbf{5 c}$ and $\mathbf{5} \mathbf{c}^{\prime}$ lie off-cycle and are unrelated to the stereochemical outcome; the product er will be related directly to the facial selectivity in the $\mathrm{Cl}$ addition step. However, the observed relationship between diastereomer
Scheme 8. Proposed Catalytic Cycles for $\alpha$-Chlorination with Catalysts 3, 9, and 10

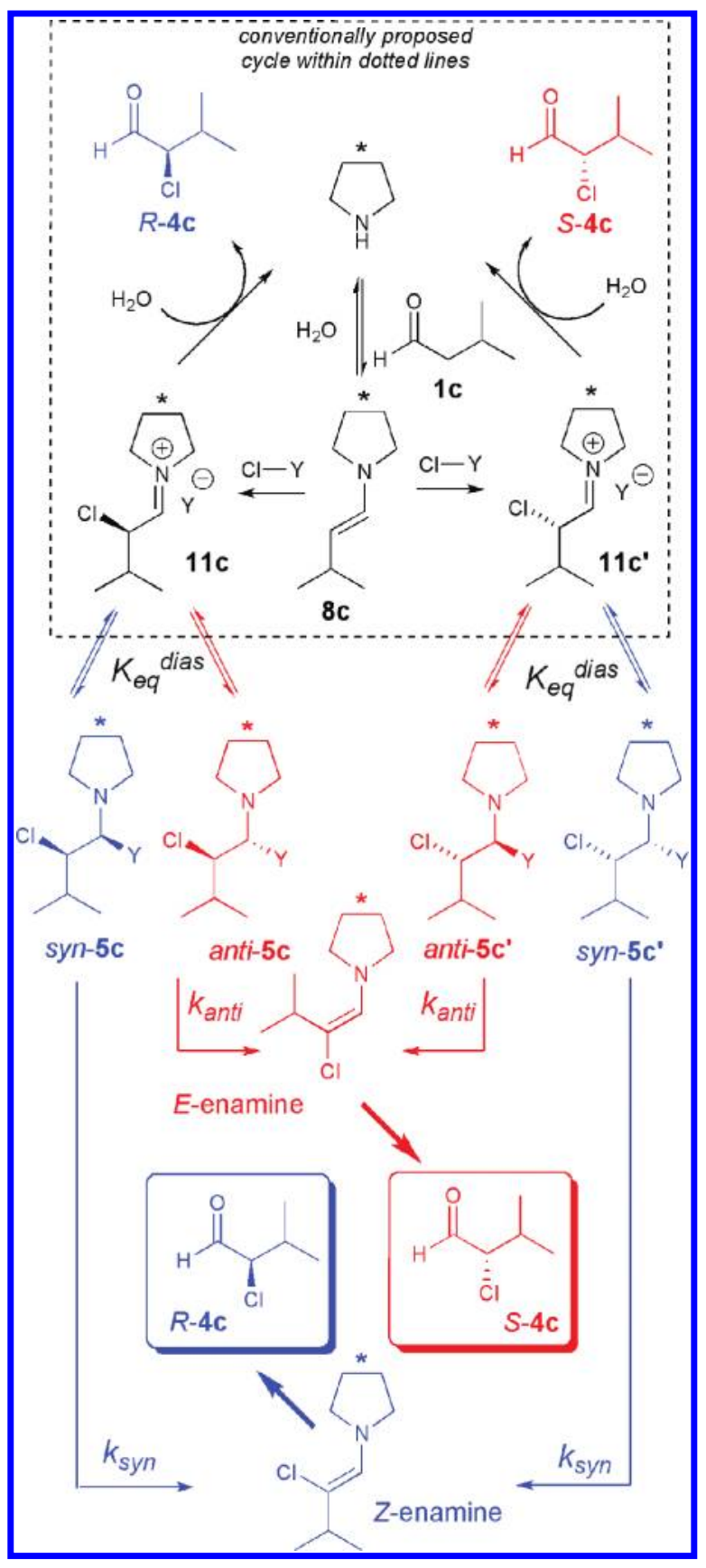

stability and product er revealed in Table 1 cannot be predicted by this mechanism.

A second difficulty with the conventionally proposed pathway is that irreversible $\mathrm{Cl}$ addition in Scheme 8 implies that the observed equilibration between the two off-cycle diastereomers occurs between those formed from addition of $\mathrm{Cl}$ to the same face of the enamine. The fact that we observe only two out of the four possible diastereomers implies near-perfect facial selectivity in the addition of $\mathrm{Cl}$ to the enamine $8 \mathrm{c}$. Thus, observation of a non-perfect er in a reaction following the conventional route should be accompanied by observation of all four diastereomeric intermediates of $\mathbf{5 c}$, in contrast to the experimental result.

The alternate proposed route places these diastereomers on the catalytic cycle itself, with the steps to product through these 
species envisioned as shown in Scheme 8. Facial attack of the enamine proceeds exclusively by either the left or the right pathway, to form $11 \mathrm{c}$ or $11 \mathrm{c}^{\prime}$, respectively, which equilibrates between one of the two possible syn and one of the two possible anti diastereomers of 5c. E2 elimination of the leaving group $\mathrm{Y}$ from these species would yield the $Z$-enamine from syn-5c and the $E$-enamine from anti-5c. Invoking stereospecific reaction of these enamines, as we demonstrated for analogous product enamine species in the conjugate addition to nitroolefins, implies that product $R-4 \mathrm{c}$ results from the former and product $S$-4c from the latter, as shown in Scheme 8. No species have been observed downstream from the diastereomers $\mathbf{5 c}$, supporting the suggestion that elimination of the leaving group $\mathrm{Y}$ is the rate-determining step in a pathway to product through these diastereomers. As suggested previously, this mechanism is consistent with both the different absolute rates for $\mathbf{2 b}$ and $\mathbf{2 c}$ as electrophiles and the zero-order kinetics in electrophile concentration.

This reaction scheme represents a further example of a Curtin-Hammett scenario, where the kinetic and thermodynamic components of product enantioselectivity are shown in eq 2 for the network in Scheme 8. The er is given by the

$$
\begin{aligned}
& e r=\frac{[R-4 \mathrm{c}]}{[S-4 \mathrm{c}]}=\frac{k_{s y n}}{k_{\text {anti }}} \cdot \frac{[\text { syn }-5 \mathrm{c}]}{[\text { anti }-5 \mathrm{c}]}=\frac{k_{\text {syn }}}{k_{\text {anti }}} \cdot K_{\text {eq }}^{\text {dias }} \\
& \text { er }=\frac{[R-4 \mathrm{c}]}{[S-4 \mathrm{c}]}=\frac{k_{s y n}}{k_{\text {anti }}} \cdot \frac{\left[\text { syn }-5 \mathrm{c}^{\prime}\right]}{\left[\text { anti }-5 \mathrm{c}^{\prime}\right]}=\frac{k_{\text {syn }}}{k_{\text {anti }}} \cdot K_{\text {eq }}^{\text {dias }}
\end{aligned}
$$

relative concentrations of the two diastereomers of $\mathbf{5 c}$ and the relative rates of Y-elimination to form the product enamines. Since the absolute stereochemistry of the observed diastereomers is unknown, eq 2 is written for each of the two possible syn:anti pairs arising from opposite facial selectivity in enamine attack on $\mathrm{Cl}$.

This Curtin-Hammett scenario provides a reasonable mechanistic alternative to model II for rationalizing the differences in enantioselectivity observed comparing catalysts 3, 9, and 10 in Table 1 . The close correlation observed between the er and $K_{\text {eq }}^{\text {dias }}$ in all examples in Table 1 implies that the rate of elimination of the leaving group is similar for the syn and anti diastereomers, or $k_{\text {syn }} \approx k_{\text {anti }}$ in eq 2 . In this case the relative stability of the two diastereomers is in direct proportion to the er and serves as the primary stereocontrolling factor. This helps to explain the higher selectivity achieved with catalyst 10, less bulky but arguably sterically more complex than catalysts 3 or 9, which is difficult to rationalize by model II.

Thus we may conclude that the near-perfect facial selectivity initially achieved in the addition of $\mathrm{Cl}-\mathrm{Y}$ in Scheme 8, required to rationalize observation of only two of the four diastereomers of $\mathbf{5 c}$, in fact can give way to an erosion of product er downstream, due to the opposite stereochemistry predicted from reaction of the syn and anti diastereomeric intermediates.

Generality. The preceding examples offer experimental evidence illustrating two subtly different scenarios where equilibrating intermediate species formed downstream from the stereogenic center-forming step may influence the stereochemical outcome. In the conjugate addition of linear aldehydes to nitroolefins, product stereoselectivity was found to be dictated by a single highly stable diastereomer existing as the on-cycle resting state equilibrated with upstream intermediates. In principle, such a scenario would allow imperfect facial selectivity to be enhanced by channeling intermediates from both sides of the cycle to product through this stable species on one side of the network. In the second example of the $\alpha$-chlorination of aldehydes, the opposite scenario was revealed: near-perfect facial selectivity in attack of the enamine could be eroded by the competitive reactions of equilibrated intermediates formed subsequent to the irreversible addition of the electrophile. It is noteworthy that in both cases, simple consideration of the transition state for the stereogenic center-forming step was found to be inadequate to explain the observed stereochemical outcome. Evocation of the Curtin-Hammett principle, in which both relative stability and reactivity of kinetically competitive species must be considered, allows rationalization of the experimental results.

These results raise a question of the generality of this Curtin-Hammett paradigm in organocatalysis. Precedent exists in a number of other organocatalytic reactions with the potential to exhibit intermediates downstream from the stereogenic center-forming step. Early model calculations by $\mathrm{Houk}^{3 \mathrm{a}}$ predicted that analogous oxetane species would form from the collapse of iminium ion intermediates in amine-catalyzed aldol reactions (Scheme 9a). Azetidine intermediates have been

\section{Scheme 9. Intermediates Identified Subsequent to the} Stereogenic Center-Forming Step in Reactions between Enamines and Electrophiles: (a) Ref 3a, (b) Ref 29, (c) Ref 30, and (d) This Work ${ }^{11}$

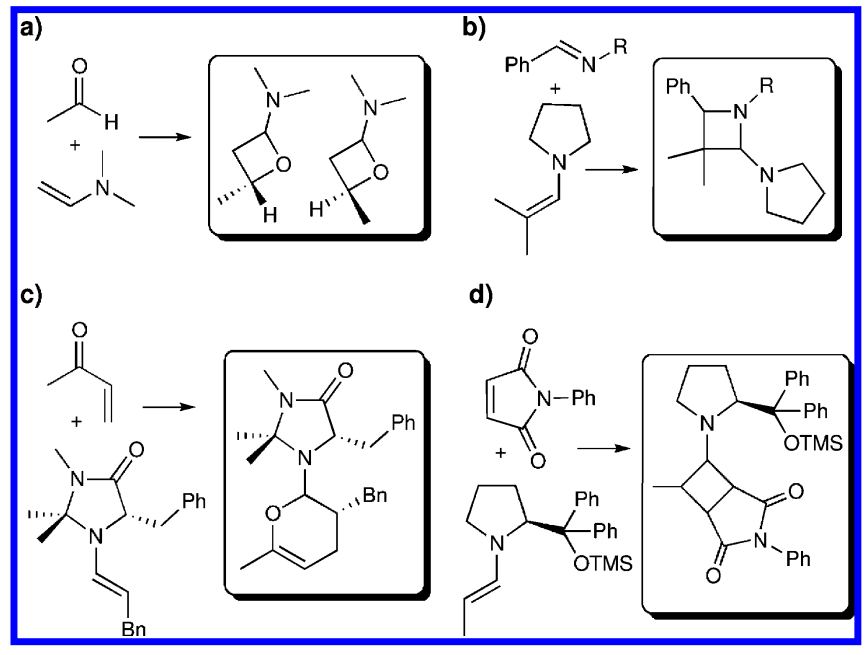

isolated in stoichiometric reactions between enamines and imines (Scheme 9b), ${ }^{29}$ suggesting that such intermediates may be viable in catalytic Mannich reactions. Gellman reported observation of a dihydropyran in the aldehyde-enone Michael addition catalyzed by a MacMillan imidazolidinone (Scheme $9 \mathrm{c}$ ) ${ }^{30}$ We identified a single stable cyclic intermediate in the reaction of a maleimide with 8 , the enamine formed from $1 \mathrm{a}$ and 3 (Scheme $9 \mathrm{~d}$ ), ${ }^{11}$ a reaction that has been shown to proceed with high enantioselectivity. ${ }^{31}$

While the cases shown in Scheme 9 all reveal cyclic intermediates in addition reactions with $\mathrm{X}=\mathrm{Y}$ electrophiles, our results in the $\alpha$-chlorination of aldehydes imply a more general role may also exist in enamine catalysis for downstream intermediates that are not cyclic and in reactions that involve substitution with $\mathrm{X}-\mathrm{Y}$ electrophiles. The potential for such species to influence the stereochemical outcome of the reaction is currently unexplored and will depend in each case both on the relative stability and reactivity of the diastereomers formed and on whether they lie on or off the catalytic cycle. 
Further kinetic and spectroscopic investigations of these and other reaction systems may allow these questions to be answered. In cases where such intermediates may play a role in the stereochemical outcome, the potential exists for exploitation of these features via rational catalyst and reaction design that may ultimately lead to even more efficient and selective asymmetric organocatalytic processes than might be envisioned by consideration of the precepts of model II alone.

\section{CONCLUSIONS}

In summary, NMR spectroscopic identification of intermediate species coupled with kinetic studies help to rationalize the stereochemical outcome in two separate organocatalytic reactions, the conjugate addition of linear aldehydes to nitroolefins and the $\alpha$-chlorination of aldehydes, in a manner that could not be explained by a simple steric model of enamine attack on an electrophile as in model II. These findings address general reactivity and selectivity concepts with the proposal of a novel reaction paradigm that combines a classic Curtin-Hammett scenario with the concept of reversibility in or subsequent to the stereogenic center-forming step. Selectivity in these examples is rationalized not by comparison of transition states for formation of the stereogenic center but by the relative stability and reactivity of equilibrated downstream intermediates in the separate branches of a competitive reaction network. Such networks offer the opportunity to tune selectivity at a number of different points in the catalytic cycle and introduce additional possibilities for rational design of active and selective substrate/catalyst combinations. Experimental results are offered to suggest that this concept may apply to related reactions and thus may represent a general phenomenon for amine catalysts lacking an acidic directing proton.

\section{ASSOCIATED CONTENT}

\section{S Supporting Information}

Experimental procedures, kinetic studies, and structural NMR studies. This material is available free of charge via the Internet at http://pubs.acs.org.

\section{AUTHOR INFORMATION}

\section{Corresponding Author}

blackmond@scripps.edu

\section{Notes}

The authors declare no competing financial interest.

\section{ACKNOWLEDGMENTS}

A.A. and D.G.B. acknowledge funding from the EPSRC. J.B. acknowledges a postdoctoral fellowship from the Education Ministry of Spain (EX2009-0687) and FECYT. We acknowledge D.-H. Huang and L. Pasternack (TSRI NMR Facility) for valuable assistance with NMR spectroscopy.

\section{REFERENCES}

(1) List, B.; Lerner, R. A.; Barbas, C. F., III. J. Am. Chem. Soc. 2000, 122, 2395.

(2) Ahrendt, K. A.; Borths, C. J.; MacMillan, D. W. C. J. Am. Chem. Soc. 2000, 122, 4243.

(3) (a) Bahmanyar, S.; Houk, K. N. I. Am. Chem. Soc. 2001, 123, 11273. (b) Bahmanyar, S.; Houk, K. N.; Martin, H. J.; List, B. J. Am. Chem. Soc. 2003, 125, 2475. (c) Hoang, L.; Bahmanyar, S.; Houk, K. N.; List, B. I.Am. Chem. Soc. 2003, 125, 16. (d) List, B.; Hoang, L.; Martin, H. J. Proc. Natl. Acad. Sci. U.S.A. 2004, 101, 5839. (e) Clemente, F. R.; Houk, K. N. Angew. Chem., Int. Ed. 2004, 43, 5765.

(4) (a) Palomo, C.; Mielgo, A. Angew. Chem. Int. Ed. 2006, 45, 7876. (b) Jensen, K. L.; Dickmeiss, G.; Jiang, H.; Albrecht, L.; Jorgensen, K.-A. Acc. Chem. Res. 2012, 45, 248.

(5) Seeman, J. I. Chem. Rev. 1983, 83, 83.

(6) Hayashi, Y.; Gotoh, H.; Hayashi, T.; Shoji, M. Angew. Chem., Int. Ed. 2005, 44, 4212 .

(7) Franzen, J.; Marigo, M.; Fielenbach, D.; Wabnitz, T. C.; Kjaersgaard, A.; Jorgensen, K. A. I. Am. Chem. Soc. 2005, 127, 18296.

(8) Grondal, C.; Jeanty, M.; Enders, D. Nat. Chem. 2010, 2, 167.

(9) (a) Blarer, S. J.; Seebach, D. Chem. Ber. 1983, 116, 3086. (b) Seebach, D.; Beck, A. K.; Golinski, J.; Hay, J. N.; Laube, T. Helv. Chim. Acta 1985, 68, 162. (c) Seebach, D.; Golinski, J. Helv. Chim. Acta 1981, 64, 1413.

(10) Lalonde, M. P.; Chen, Y.; Jacobsen, E. N. Angew. Chem., Int. Ed. 2006, 45, 6366.

(11) See Supporting Information for details

(12) Bures, J.; Armstrong, A.; Blackmond, D. G. J. Am. Chem. Soc. 2011, 133, 8822.

(13) Patora-Komisarska, K.; Benohoud, M.; Ishikawa, H.; Seebach, D.; Hayashi, Y. Helv. Chim. Acta 2011, 94, 719.

(14) The reversible addition of enamine $8 \mathbf{a}$ to nitrostyrene $\mathbf{2 a}$ to form cyclobutane 5a shown in Scheme 5 is likely to proceed via several sequential, but kinetically indistinguishable, elementary steps that have been combined as equilibrium constant $K_{\text {eq,5a }}$. Similar arguments apply to other steps in the cycle, including the deprotonation of cyclobutane 5a with equilibrium constant $K_{\text {eq, } 6 \mathrm{a}}$.

(15) For H/D isotope effects in carbon acid deprotonations, see: Watt, C. I. F. I. Phys. Org. Chem. 2010, 23, 561. See Supporting Information for a summary of the mathematical analysis pertaining to the results presented here.

(16) Bures, J.; Armstrong, A.; Blackmond, D. G. Chem. Sci. 2012, 3, 1273.

(17) The reverse of the catalytic cycle does not proceed further from $E-7$, whose formation in the forward cycle is irreversible under catalytic conditions.

(18) Hoops, S.; Sahle, S.; Gauges, R.; Lee, C.; Pahle, J.; Simus, N.; Singhal, M.; Xu, L.; Mendes, P.; Kummer, U. Bioinformatics 2006, 22, 3067.

(19) For example, a highly selective outcome is predicted for Pathway B in the case where the ratio $K_{\mathrm{eq}, 5 \mathrm{a}} / K_{\mathrm{eq}, 5 \mathrm{~s}^{\mathrm{a}}}$ is large, and each of the other ratios in the equation describing the er for Pathway $\mathrm{B}$ is unity (unselective).

(20) The IUPAC definition of the Curtin-Hammett principle: Gold, V.; Loening, K. L.; McNaught, A. D.; Shemi, P. IUPAC Compendium of Chemical Terminology, 2nd ed.; Blackwell Science: Oxford, 1997. Because the principle states that product selectivity depends only on $\Delta \Delta G^{\ddagger}$, it is commonly, although incorrectly, stated as a corollary that product selectivity is independent of the relative stability of intermediates. See Supporting Information for a correction of this misconception.

(21) Landis, C. R.; Halpern, J. A. I. Am. Chem. Soc. 1987, 109, 1746.

(22) Halpern, J. Science 1982, 217, 401.

(23) Ferretti, A. C.; Mathew, J. S.; Ashworth, I.; Purdy, M.; Brennan, C.; Blackmond, D. G. Adv. Sunth. Catal. 2008, 350, 1007.

(24) Zhang, W.; Lee, N. H.; Jacobsen, E. N. J. Am. Chem. Soc. 1994, $116,425$.

(25) Ozawa, F.; Kubo, A.; Matsumoto, Y.; Hayashi, T. Organometallics 1993, 12, 4188.

(26) There are a number of diastereomeric possibilities for cyclobutane 5a', which is not observed experimentally. We suggest that the most likely lowest energy alternative exhibits all configurations in the cyclobutane ring reversed from that of $\mathbf{5 a}$.

(27) Brochu, M. P.; Brown, S. P.; MacMillan, D. W. C. J. Am. Chem. Soc. 2004, 126, 4108.

(28) (a) Halland, N.; Braunton, A.; Bachmann, S.; Marigo, M.; Jorgensen, K. A. I. Am. Chem. Soc. 2004, 126, 4790. (b) Halland, N.; 
Alstrup Lie, M.; Kjaersgaard, A.; Marigo, M.; Schiott, B.; Jorgensen, K. A. Chem.-Eur.I. 2005, 11, 7083.

(29) Alben, R. W. M.; Smit, R.; Scheeren, J. W. J. Org. Chem. 1987, $52,365$.

(30) Peelen, T. J.; Chi, Y.; Gellman, S. H. J. Am. Chem. Soc. 2005, $127,11598$.

(31) Zhao, G. L.; Xu, Y.; Sunden, H.; Eriksson, L.; Sayah, M.; Cordova, A. Chem. Commun. 2007, 734. 